\title{
Understanding the High-Temperature Mechanical Properties of A710 (HSLA-80) Steel With Use of Complementary Atom Probe Tomography and Electron Microscopy
}

\author{
Ann N. Chiaramonti ${ }^{1}$, Jeffrey W. Sowards ${ }^{1}$, Daniel K. Schreiber ${ }^{2}$, and James R. Fekete ${ }^{1}$ \\ ${ }^{1}$ Applied Chemicals and Materials Division, Material Measurement Laboratory, National Institute of \\ Standards and Technology, Boulder, CO USA. \\ ${ }^{2}$ Energy \& Environment Directorate, Pacific Northwest National Laboratory, Richland, WA USA.
}

Alloy ASTM A710 (HSLA-80) is a co-precipitation hardened steel with a desirable combination of mechanical properties and weldability, making it an excellent candidate for use in structural applications such as bridges, shipbuilding, and pipelines. There have been extensive studies of the strengthening mechanisms, effect of heat treatment and continuous cooling, and kinetics of the precipitation process in this and similar materials, but little work has been performed to understand the high-temperature mechanical properties [1-6]. Understanding the effect of high temperatures on the mechanical properties of these and similar alloys is very important in terms of engineering for structural integrity and well-understood failure mechanisms in a fire. In this study we use local-electrode atom probe tomography, transmission electron microscopy, and optical metallography as complementary techniques that lend fundamental insight into the high-temperature mechanical behavior of A710 on multiple length scales.

High-temperature tensile testing revealed a significant drop in the percent reduction in area of this material at temperatures above $500{ }^{\circ} \mathrm{C}$ (Fig 1a). Optical images of the necked region at each testing temperature, superimposed on the high-temperature tensile testing data (Fig 1b), demonstrate this dramatic embrittlement. Fractography of necked regions indicated that below the critical temperature of $500{ }^{\circ} \mathrm{C}$, fracture was primarily ductile in nature, while above $500{ }^{\circ} \mathrm{C}$, fracture was brittle and intergranular. The intergranular fractures were located along ferrite grain boundaries.

The nominal diameter of $\mathrm{Cu}$ precipitates in this material, based on TEM imaging of as-received specimens (not heat treated), was less than $10 \mathrm{~nm}$. Atom probe analyses revealed an overall coarsening of the $\mathrm{Cu}$ precipitates upon exposure to elevated temperature (Fig 2). Analysis of interfaces at 6 at. \% $\mathrm{Cu}$ revealed the average surface area of a $\mathrm{Cu}$ precipitate increased by nearly four times between room temperature and $650{ }^{\circ} \mathrm{C}$. Additional results of correlative atom probe tomography and transmission electron microscopy will be discussed in detail, particularly relating the change in size and distribution of the co-precipitation strengthening particles (copper and $\mathrm{NbC}$ ) to the observed high-temperature mechanical properties [7-8].

\section{References:}

[1] SW Thompson and G Krauss, Metallurgical and Materials Transactions A 27A (1996) p. 1573.

[2] MS Gagliano, and ME Fine, Calphad 25 (2001) p. 207.

[3] A Deschamps et al., ISIJ International 41 (2001) p. 196.

[4] A Deschamps et al., ISIJ International 43 (2003) p. 1826.

[5] MS Gagliano and ME Fine, Metallurgical and Materials Transactions A 35A (2004) p. 2323.

[6] ME Fine and D Isheim, Scripta Materialia 53 (2005) p. 115. 
[7] Some of the atom probe work performed for this research was on an instrument supported under NSF Award No. 1040456.

[8] This work is a contribution of NIST, an agency of the United States government. As such, it is not subject to copyright in the United States.
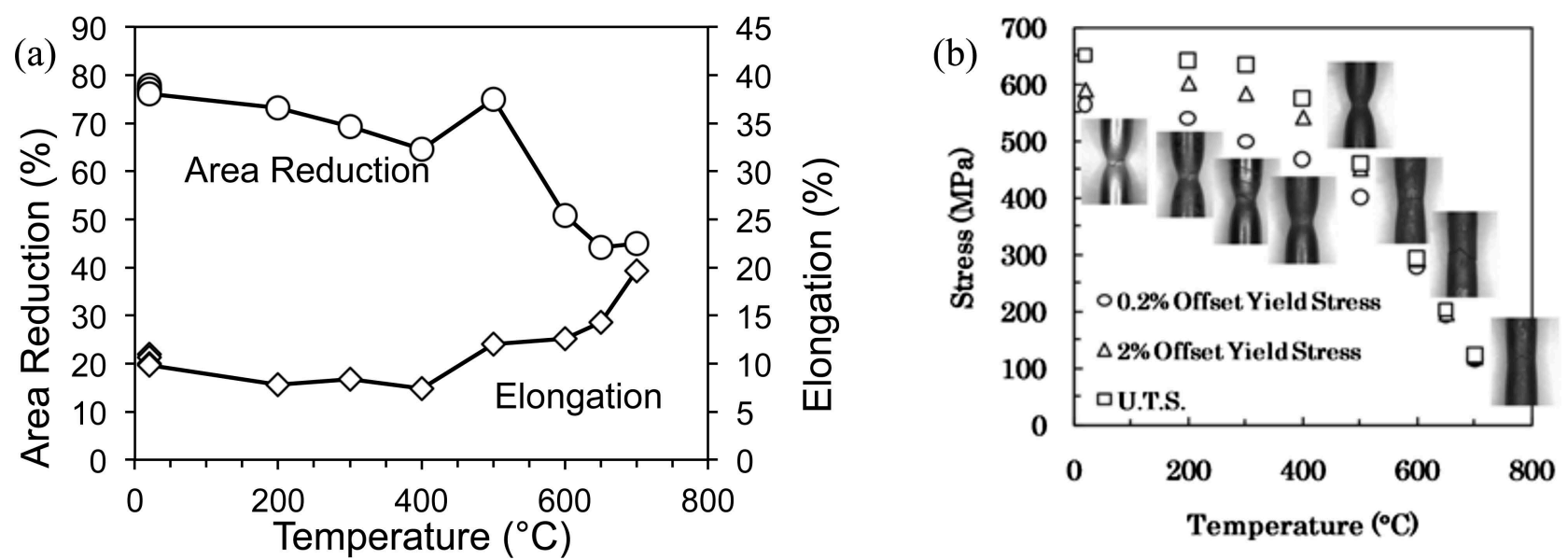

Figure 1. (a) Percent reduction in area (circles) and percent elongation (diamonds) as a function of tensile testing temperature for A710 steel. (b) Optical images of the fractured tensile specimens superimposed on the mechanical testing data for A710 at various tensile testing temperatures. The post-test specimen diameter changed substantially near $500{ }^{\circ} \mathrm{C}$, which corresponds to the predominant fracture mechanism transitioning from ductile to brittle. For scale, the diameter of the unstrained area of the room temperature tensile specimen is nominally $6 \mathrm{~mm}$.

(a)

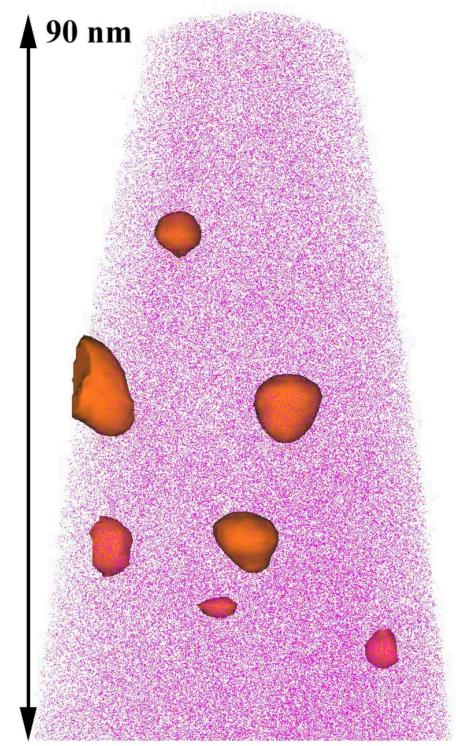

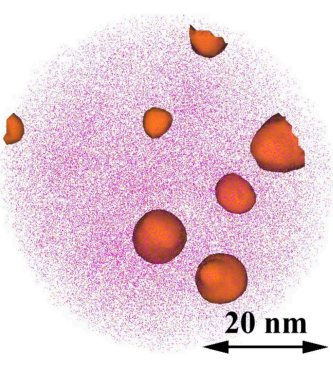

(b)

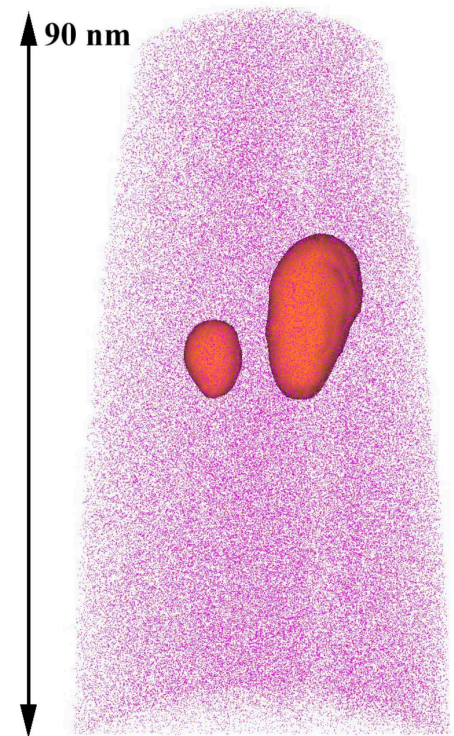

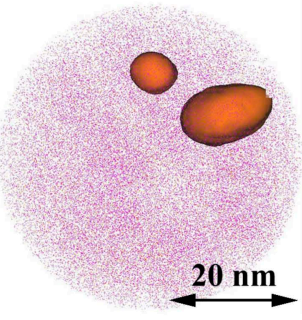

Figure 2: Side and top view atom probe reconstructions for specimens tested at (a) room temperature and (b) $650{ }^{\circ} \mathrm{C}$, which show 6 at. \% $\mathrm{Cu}$ isoconcentration surfaces (orange). Iron atoms are shown in purple. These particular samples were prepared from an unstrained region of the tensile specimen. 